\title{
Style in Song Lyrics Berkelana Ke Ujung Dunia By Susilo Bambang Yudhoyono (Stylistics Analysis)
}

\author{
Erna Erpiana*) \\ Universitas Negeri Jakarta, Pascasarjana \\ Yumna Rasyid \\ Universitas Negeri Jakarta \\ Zuriyati \\ Universitas Negeri Jakarta
}

*) Jl. Rawamangun Muka, Jakarta Timur, DKI Jakarta, 13220, Indonesia; e-mail: ernaerpiana_pb14s2@mahasiswa.unj.ac.id

\begin{abstract}
Abstrack. Style of language can be interpreted as an individual way of expressing ideas or characteristics of how individuals communicate. A politician has his own style, even the head of state, community leaders and even writers. The essence is that nothing is really the same in someone's style, both when speaking and writing. In stylistic studies it is often referred to as a linguistic approach to literature, because literature is inseparable from the medium of language. This paper will discuss the style of language in the lyrics of the song Berkelana ke Ujung Dunia by Susilo Bambang Yudhoyono. Song lyrics are considered to be the same as poetry, so the study of song lyrics is right using stylistic studies with the method of content analysis. The purpose of this study is to describe: (1) the style of words in the song Berkelana ke Ujung Dunia; (2) The sentence style in the song Berkelana ke Ujung Dunia; (3) Figure of speech in the song Berkelana ke Ujung Dunia. Keywords: Stylistics, song lyrics, words, sentences, figure of speech.
\end{abstract}

Article History: Received: 22/05/2019; Revised: 23/06/2019; Accepted: 05/07/2019; Published: 31/07/2019. How to Cite (MLA $7^{\text {th }}$ ): Erpiana, Erna, Yumna Rasyid, and Zuriyati. “Style in Song Lyrics Berkelana ke Ujung Dunia by Susilo Bambang Yudhoyono (Stylistics Analysis)." Hortatori Jurnal Pendidikan Bahasa dan Sastra Indonesia 3.01 (2019): 1-6. Print/Online. Copyrights Holder: Erna Erpiana, Yumna Rasyid, Zuriyati. First Publication: Hortatori Jurnal Pendidikan Bahasa dan Sastra Indonesia (2019).

This work is licensed under a Creative Commons Attribution-ShareAlike 4.0 International License.

\section{Pendahuluan}

Sastra dan peradaban sejatinya adalah satu kesatuan yang tidak pernah lepas bagai dua sisi mata uang. Layaknya peradaban yang terus berkembang dari masa ke masa, sastra pun demikian. Kekayaan, keragaman, dan kajian-kajian sastra pun semakin berkembang dan terus terasa kebermanfaatannya. Memasuki era digital seperti saat ini, arus deras yang memudahkan akses informasi apapun, bukan tidak mungkin sesuatu akan cepat popular, namun cepat pula tenggelam. Hal itulah yang ditakutkan pada karyakarya sastra. Banyak lahir karya-karya sastra, namun tidak ternikmati karena tertimbun oleh derasnya arus informasi digital yang kemudian dikhawatirkan akan mengikis keberadaan karya-karya sastra yang semestinya memperkaya khazanah ilmu pengetahuan. Dalam pembelajaran puisi di sekolah-sekolah contohnya, minat dan gairah siswa dalam membaca, memahami, bahkan menghayati puisi-puisi sastrawan angkatan lama, nampak terasa menyulitkan bagi mereka. Terdapat beberapa faktor mengenai masalah minat memahami dan menghayati puisi tersebut diantaranya proses pembelajaran sastra yang monoton, guru yang terkadang dianggap belum mampu menghadirkan atmosfer pengajaran sastra, atau objek yang dianggap 
tidak menarik. Selain itu, pembedahan sebuah puisi ketika mereka mengidentifikasi tema, makna, serta amanat yang terkandung dalam isi puisi juga terkadang masih kesulitan. Perhatian mengenai pedoman pembelajaran puisi sangat penting, hal tersebut juga tidak lepas dari puisi apa dan bagaimana yang sekiranya cocok dijadikan bahan pembelajaran puisi khususnya jika menelisik kembali bahwa saat ini sudah era digital, yang mana tidak cukup jika hanya menggunakan puisi-puisi lama sebagai bahan pembelajaran. Haneuer (2004:8) menyampaikan, "Poetry is all around us. It is on television and the radio in popular songs; it is political speeches; it is in religious services; and it is present at all sorts of public and family occasions." Berkaitan dengan hal tersebut, puisi termasuk dalam salah satu karya sastra yang berbeda dengan karya fiksi lainnya, menggunakan bahasa yang dipadatkan, memiliki irama yang padu dalam pengungkapan bahasanya. Selain itu Haneur (2004:8) juga mengemukakan, "Poetry also helps students develop language skills in a uniqe fashion." Puisi dianggap membantu siswa mengembangkan keterampilan berbahasa yang unik. Hanya saja, penghayatan dalam karya sastra khususnya puisi memberikan dampak penting, karena selain memberikan penghargaan pada sebuah karya, juga terdapat nilai-nilai baik yang memberikan efek baik terhadap pembentukan karakter. Penghayatan gaya bahasa juga akan memberikan sisi sensitifitas terhadap sosial, kecintaan terhadap bangsa dan lain-lain, sehingga pembelajaran sastra di sekolah bukan hanya semata objek belajar saja, namun harus mengandung nilai-nilai di dalamnya. Lirik lagu memang dapat dijadikan sebagai penyampaian gagasan, pesan untuk para pendengar, bahkan sebagai media pembelajaran agar lebih mudah diingat dan menyenangkan, karena di dalam lagu terdapat unsur menghibur. Bukan hanya sekadar menghibur saja, lagu bahkan dapat memberikan gambaran situasi sosial masyarakat yang sedang terjadi. Lebih tinggi daripada itu, lagu dapat menjadi alat komunikasi untuk mengajak pendengarnya sesuai yang diinginkan pencipta lagu, terkadang bagi sebagian orang, lagu sangat berpengaruh untuk diri dan cerminan kepribadiannya. Sehingga dalam hal ini, lirik lagu karya Susilo Bambang Yudhoyono dapat dijadikan sebagai materi pembelajaran sastra khususnya pada Kurikulum 2013 dengan silabus pendidikan SMA kelas X ranah kompetensi dasar yang harus dicapai siswa pada KD 3.16 yaitu "Mengidentifikasi suasana, tema, dan makna beberapa puisi yang terkandung dalam antologi puisi yang diperdengarkan atau dibaca". Kajian stilistika digunakan dalam penelitian ini karena stilistika dapat menjadi instrument untuk lebih memahami suatu karya sastra, dan pemahaman yang lebih baik, sehingga pembaca memberi apresiasi dan penilaian secara benar, diungkapkan oleh Norgard (2010:1) menjelaskan, "Stylistics is the study of the ways in which meaning is created through language in literature as well as in other types of text." Bahwa stilistika adalah studi mengenai bagaimana cara makna dibentuk melalui bahasa dalam sastra dan teks-teks jenis lain. Hal yang sering menjadi pertanyaan apakah stilistika kajian berlandaskan pada estetika atau lingustik. Maka Spitzer dalam Leech (2007:12) menyampaikan keterkaitan antara linguistik-sastra dan juga tugas kajian stilistika adalah kemampuan merespons sastra yang diamati. Berikut adalah siklus yang dijelaskan oleh Spitzer:

Berdasarkan pengamatan dari lingkaran di atas, dapat dipahami guna mengapresiasi sastra dalam

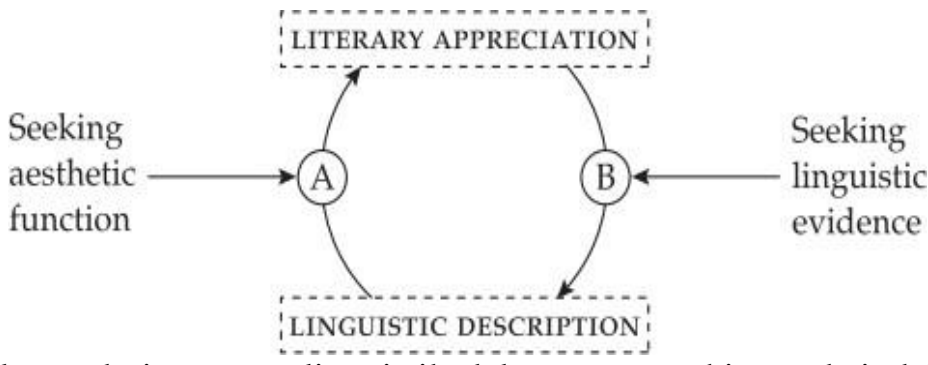

kajian stilistika tidak lepas dari peranan linguistik dalam sastra sehingga keindahan dalam sastra akan terkupas berdasarkan deskripsi linguistik. Nurgiantoro (2017:96) menjelaskan, langkah kajian stilistika adalah untuk mengapresiasi teks sastra. Pertama, guna menjawab apakah teks tersebut mengandung keindahan namun juga tepat sebagai sarana berkomunikasi. Kedua, mencari bukti-bukti linguistik yang dipertimbangkan mendukung tujuan pertama, aspek yang dianalisis untuk teks sastra adalah aspek bunyi, diksi, struktur, bahasa figuratif (majas), sarana retorika, serta konteks dan kohesi, aspek bunyi penting dalam teks puisi misalnya persajakan dengan variasinya, irama, tiruan bunyi, dan penciptaan suasana.

Dikutip dalam Rohman (2018:54-60) penjabaran aspek-aspek kajian stilistika yang akan dibedah merupakan tiruan bunyi, kata, dan kalimat. Data yang hendak diambil dalam tiruan bunyi adalah tiruan 
bunyi yang hadir dalam narasi tentang orang, hewan, atau hal-hal yang terkait bunyi-bunyi tertentu sebagai ekspresi khas. Selanjutnya adalah kata yang akan diutamakan dalam kajian stilistika adalah kata yang mengandung metafora tentang sesuatu, atau mungkin dengan variasi yang lain seperti personifikasi, sinestesia, simile, perifrasis, dan sejenisnya. Berikutnya adalah kalimat yang menjelaskan suatu gagasan tertentu atau menceritakan peristiwa.

Sedangkan Norgard (2010:1) memandang analisis stilistika adalah cara makna dibentuk pada teks sastra dan teks lain, fokus kajian pada fitur-fitur teks fonologi, leksikal, gramatikal, semantik, pragmatik, atau wacana dan aspek kognitif lainnya. Selain itu Nogard membagi perbedaan kajian bidang stilistika lebih luas lagi seperti adanya stilistika kognitif, feminis, pragmatik, multimodal dan historis. Berikutnya adalah stilistika Leech (2007:61) mengklasifikasikan kajian stilistika dalam empat fokus, yaitu kategori leksikal, kategori gramatikal, figure of speech, serta kehesi dan konteks.

Terlihat perbedaan dari beberapa pandangan di atas mengenai kajian stilistika. Penulis tentu perlu memilih model kajian stilistika yang cocok untuk analisis pada lirik lagu. Dengan demikian, stilistika model Leech menjadi model kajian yang dipilih karena terdapat fokus kajian bahasa figuratif (pemajasan) yang dibutuhkan dalam analisis lagu guna melihat gaya bahasa yang mendominasi dalam lirik lagu tersebut. Akan tetapi, tidak semua fokus kajian akan dipakai penulis, karena unsur kajian kohesi dan koherensi biasanya digunakan pada kajian teks wacana. Sehingga untuk kajian lirik lagu dengan model stilistika Leech at.al yang difokuskan adalah unsur bunyi, leksikal, gramatikal, dan pemajasan. Pendeknya, untuk mengetahui bagaimana style atau gaya Susilo Bambang Yudhoyono dalam bersastra akan dilihat dari tiga aspek, yaitu bagaimana gaya kata dalam lirik lagu, bagaimana gaya kalimat dalam lirik lagu dan bagaimana figure of speech atau majas dalam lirik lagu.

\title{
Metode
}

Penelitian ini menggunakan kajian stilistika dengan metode analisis isi (content analysis). Model stilistika yang digunakan adalah model Leech yang mengandung empat kriteria kebahasaan yaitu leksikal (diksi), gramatikal (kalimat), figure of speech (majas), serta kohesi dan koherensi. Namun seperti yang disudah dipaparkan sebelumnya bahwa kohesi dan koherensi tidak dilibatkan dalam kajian ini. Berikut adalah landasan pedoman penelitian dari model stilistika Leech. Berikut adalah data penelitian lirik lagu karya Susilo Bambang Yudhoyono yang berjudul Berkelana ke Ujung Dunia yang terdapat dalam album Harmoni Cinta Alam dan Kedamaian.

$$
\begin{gathered}
\text { Berkelana ke Ujung Dunia } \\
\text { (Susilo Bambang Yudhoyono) }
\end{gathered}
$$

Ke puncak gunung tinggi ku mendaki

Menembus langit biru tak berbatas

Awan-awan datang dan menyapa

Di bawah sinar surya yang perkasa

Ku arungi laut luas di seberang

Tak takut walau ada badai dan topan

Burung-burung terbang bernyanyi riang

Di atas karang dan ombak berkejaran

\author{
Ayo kawan berkelana \\ Sampai ujung dunia kita \\ Jangan ragu atau bimbang \\ Siapa berani akan menang
}

\section{Hasil dan Diskusi}

A. Gaya diksi 
Leech at.al menjelaskan bahwa dalam kategori leksikal secara general, kajian merujuk pada; umum atau spesifik. Seberapa jauh penulisnya memanfaatkan asosiasi emosi dan kata-kata lain. Lalu, apakah teks mengandung frase idiomatik atau kolokasi penting.

Pada bait pertama, larik pertama terdapat frasa puncak gunung yang merupakan frasa idiomatik, karena bukan puncak gunung sesungguhnya yang dimaksud melainkan kehidupan yang sulit ditaklukan dengan gambaran seperti puncak. Selanjutnya diperdalam dengan kata mendaki dalam kosa kata ini bukan gambaran mendaki yang sesungguhnya melainkan menjadi hidup. Pada larik kedua, terdapat frasa idiomatik menembus langit biru yang dimaksudkan dalam hal ini bukan menembus yang sesungguhnya dengan terbang ke langit biru, melainkan lebih tinggi lagi dari makna mendaki puncak gunung tadi, penulis ingin menyampaikan bahwa kehidupan tidak cukup sampai di sana, namun harus lebih tinggi lagi sampai langit, hal itu diperkuat oleh frasa idiom yang selanjutnya yaitu tak berbatas inilah gambaran langit yang memang tidak memiliki batas. Selanjutnya dijelaskan pada larik ketiga ada frasa awan-awan datang yang memberikan gambaran keindahan alam dalam sebuah perjalanan pasti akan dinikmati dalam hal ini adalah pengalaman hidup diperkuat dengan kata dan menyapa artinya gambaran seperti sesame manusia yang saling mengasihi. Larik keempat adalah frasa idiom di bawah sinar surya maksudnya merupakan matahari yang menyinari bumi, artinya manusia yang selalu hidup di bawah sinar matahi yang memberikan cahaya tanpa henti atau harapan, selanjutnya kata yang perkasa ini memperjelas mengenai kekuatan sinar mentari yang tidak pernah lenyap dengan kekuatannya yang besar sehingga menghantarkan semangat.

Pada bait kedua, larik pertama terdapat idiom laut luas ini tentu masih bertalian makna dengan bait pertama, karena laut yang dimaksud bukan laut yang sesungguhnya melainkan masih tentang kehidupan yang diarungi atau dilalui, kata di seberang menggambarkan perjalanan yang jauh. Pada larik ketiga terdapat kata badai dan topan juga bukan makna sebenarnya, melainkan rintangan dan ujian yang besar dalam kehidupan. Lalu pada larik ketiga burung-burung terbang dan kata bernyanyi riang merupakan idiom yang menjelaskan keindahan alam, artinya berdampingan dengan kesulitan ada pula keindahan yang dapat dinikmati layaknya pada larik keempat pada idiom ombak berkejaran membuat indera penglihatan terasa memandang keindahan alam.

Pada bait ketiga, larik pertama terdapat kata berkelana dapat dimaknai berjuang dalam kehidupan, dapat juga dimaknai merantau. Hal tersebut ditandai dengan larik kedua yang menyebutkan sampai ujung dunia pada larik ini terdapat kata ujung dunia yang artinya sangat jauh dan tidak tengjangkau mata, namun penulis ingin memberikan kesan petualangan yang tiada batas, atau sangat luas. Dalam petualangan yang amat jauh penulis nampaknya sudah menduga ada kekhawatiran yang terbersit dalam benak setiap orang maka dipertegas dengan larik ketiga yang menyampaikan jangan ragu hal ini menggambarkan adanya dorongan kuat yang diberikan penulis bahkan ada pula kata atau bimbang. Setiap perjuangan harus membuahkan hasil begitulah penulis sampaikan pada larik keduabelas yang menyampaikan idiom siapa berani dalam hal ini merupakan frasa yang memberikan tantangan dengan hasil yang menggembirakan yaitu frasa akan menang. Maka keraguan tersebut harus dihilangkan dengan adanya frasa yang mempertegas yaitu bulatkan hati yang mengajak pada pendengar untuk memantapkan langkahnya juga dengan tidak lepas pada peran Tuhan yang akan membuat manusia menjadi lebih damai dengan adanya frasa berkah Tuhan. Akhir dari bait ini ada satu larik tambahan yaitu jangan ragu kita menang sebagai penegas dari akhir penutup puisi ini yang menggambarkan kekuatan kebersamaan dengan menggunakan kata kita karena penulis ingin menggambarkan perjuangan akan ringan jika dikakukan bersama.

\section{B. Gaya kalimat}

Leech at.al Dalam kajian ini akan diteliti apakah penulis hanya menggunakan pernyataan (kalimat deklaratif), atau apakah pertanyaan, perintah.

1. Kalimat pernyataan

Ke puncak gunung tinggi ku mendaki

Menembus langit biru tak berbatas

Awan-awan datang dan menyapa

Di bawah sinar surya yang perkasa

$\mathrm{Ku}$ arungi laut luas di seberang

Tak takut walau ada badai dan topan 
Burung-burung terbang bernyanyi riang

Di atas karang dan ombak berkejaran

2. Kalimat pertanyaan

Siapa berani akan menang

3. Kalimat perintah

Ayo kawan berkelana

Bulatkan hati dan tekadmu

Jangan ragu kita menang!

C. Figure of Speech atau Majas

Leech at.al menyampaikan bahwa kiasan akan sering menjadi petunjuk untuk interpretasi khusus seperti metafora, metonimi, sinekdoke, paradoks, ironi, pefsonifikasi, lain-lain.

\begin{tabular}{lll} 
No & \multicolumn{1}{c}{ Lirik } & Gaya Bahasa \\
\hline .1 & Ke puncak gunung tinggi ku mendaki & Metafora \\
\hline 2 & Menembus langit biru tak berbatas & Metafora \\
\hline 3. & Awan-awan datang dan menyapa & Personifikasi \\
\hline 4. & Di bawah sinar surya yang perkasa & Personifikasi \\
\hline 5 & Ku arungi laut luas di seberang & Metafora \\
\hline 6 & Tak takut walau ada badai dan topan & Metafora \\
\hline 7. & Burung-burung terbang bernyanyi riang & Personifikasi \\
\hline 8 & Di atas karang dan ombak berkejaran & Personifikasi \\
\hline 9 & Ayo kawan berkelana sampai ujung dunia kita & Metafora \\
\hline 10 & Jangan ragu atau bimbang & - \\
\hline 11. & Siapa berani akan menang & Metafora \\
\hline 12. & Bulatkan hati dan tekadmu & Litotes \\
\hline 13 & Berkah Tuhan selalu bersamamu & Litotes \\
\hline 14 & Jangan ragu kita menang! & - \\
\hline
\end{tabular}

\section{Simpulan}

Lirik lagu sama halnya dengan puisi dapat menjadi kajian yang dikupas dengan kajian puisi sehingga efek keindahannya makin dapat dirasakan. Gaya berpuisi Susilo Bambang Yudhoyono yang notabene adalah seorang negarawan memang tidak lepas dari gaya yang bersemangat, membangun karakter positif dan kental akan nuansa perjuangan. Dalam kajian ini telah ditemukan adanya gaya bahasa personifikasi dan metafora yang dominan, kajian ini diharapkan dapat menjadi alternatif pembelajaran sastra khususnya puisi di SMA yang diterapkan pada Kurikulum 2013 merujuk pada KD 3.16 yaitu "Mengidentifikasi suasana, tema, dan makna beberapa puisi yang terkandung dalam antologi puisi yang diperdengarkan atau dibaca". Selain itu, diharapkan dengan penggunaan lirik lagu ini dapat menumbuhkan rasa kecintaan terhadap alam karena lirik lagu ini kental dengan unsur cinta kepada alam

\section{Ucapan Terima Kasih}

Rasa Syukur dan bangga tidak lupa saya haturkan kepada kedua pembimbing saya yaitu Prof. Dr. Yumna Rasyid, M.Pd dan Prof. Dr. Zuriyati, M.Pd. berkat dukungan dan arahan dari beliau penelitian ini dapat terselesaikan dengan baik dan seperti tujuan yang diharapkan, dengan adanya penelitian ini semoga dapat dimanfaatkan guna kekayaan ilmu dan bahan ajar sastra. 
6 Style in Song Lyrics Berkelana ke Ujung Dunia by Susilo Bambang Yudhoyono (Stylistics Analysis)

\section{Daftar Rujukan}

Hanauer, David Ian. Poetry and The Meaning of Life: Reading and Writing Poetry in Language Arts Classrooms. Vol. 38. Pippin Publishing Corporation, 2004. Print.

Leech, Geoffrey N. Style in fiction. United Kingdom: Pearson, 2007. Print.

Norgard, Nina. Key Term in Stylistics. NewYork: Continum Publishing, 2010. Print.

Nurgiantoro, Burhan. Stilistika. Gajah Mada University Press: Yogyakarta, 2017. Print.

Rohman, S. Stilistika Posmodern. UNJ Press: Jakarta, 2018. Print. 